\title{
Analysis of the Revolutionary Game Model Between Tourism Attraction and Tourism Enterprises
}

\author{
Wenke Wang ${ }^{1,2, a}$, Ruixue Wang ${ }^{3, b}$, Shuangyu Yang ${ }^{2, c}$, Linxin Peng ${ }^{4, d}$ \\ and Bin Yan ${ }^{2, e}$ \\ ${ }^{1}$ Visual Computing and Virtual Reality Key Laboratory of Sichuan Province, Sichuan Normal \\ University, Chengdu 610068, China; \\ ${ }^{2}$ School of business, Sichuan Normal University, Chengdu 610068, China; \\ ${ }^{3}$ School of Manufacturing Science and Engineering, Sichuan University, Chengdu 610065, China; \\ ${ }^{4}$ School of Foreign Language, Sichuan Normal University, Chengdu 610068, China; \\ afinance51@126.com, ${ }^{b} 532387069 @ q q . c o m,{ }^{c} 550864516 @ q q . c o m$, \\ d493756890@qq.com, e1099348458@qq.com
}

Keywords: Disabled accessible tourism; tourism enterprise; tourist attraction; evolutionary game.

\begin{abstract}
As a thriving travel business, disabled accessible tourism has been getting more and more attention from related stakeholders in the market since the introduction of its concept and its development in China. Tourism attraction and tourism enterprises are acknowledged as the stakeholders who the disabled tourism, if taken as a product, contacts with directly while being served and sold. Therefore, this paper constructs an evolutionary game model between tourism enterprises and tourism attraction and analyzes the evolutionary stable strategy and key influence factors of the two parties when developing the disabled travel business. The research results show that to develop the disabled tourism needs the cooperation of tourism attraction and enterprises. The enterprises should increase their communication with tourism attraction to decrease unnecessary lose and simultaneously optimize their service quality while managing to strengthen business integration. The tourism attraction should construct barrier-free facilities in accordance with government's policy, improve their profession of the disabled tourism, and intensify the propaganda of this business.
\end{abstract}

\section{Introduction}

In June 2012, the State Council promulgated Regulation on the Barrier-free Environment Construction, and in 2013 its General Office issued Outline of National Leisure and Tourism (2013-2020) . Thus the disabled accessible tourism has been further developed. However,from another point of view, it can be seen that the disabled tourism is still limited in the sphere of public welfare and hasn't gone to market. Tourism attraction and enterprises are the main parties to maintain the balanced development of the market, while among the existing literature, few have taken the two groups as main research objects to discuss the development issues of the disabled tourism and made specific measurement of the benefits and costs of the two profit-driven organizations while developing the business. However, the conditions which make the two stakeholders mutually restricted and helpful are needed for the long-term development of the disabled tourism to realize mutual benefit and win-win result through coordinating their conflicts. This paper adopts an asymmetric revolutionary game model to analyze the stable state in the situation that the two stakeholders are mutually restricted and connected when developing the disabled tourism in the hope of providing theoretical basis and decision support to realize the disabled tourism .

\section{Research Process}

Problem Research. Currently most domestic activities of the disabled tourism are public welfare mainly organized by the utility departments of government or public welfare social groups, 
sometimes supported by tourism enterprises. Although a small part of travel agencies want to undertake activities of the disabled tourism out of social responsibility and in consideration of brand images equipping facilities for the disabled tourists, needs of professional caregivers and other requirements bring great challenges to tourism enterprises to do so, and thus there are few in China which engaged in the business in consideration of high cost and risk. Therefore only relying on tourism enterprises' spontaneous actions hardly can the disabled tourism continue a long-term growth. The problem faced by tourism attraction in current stage primarily is the high cost of barrier-free facilities. China didn't promulgate Regulation on the Barrier-free Environment Construction until in 2012. Some advanced barrier-free equipment can only be got through importation for domestic researches on developing the facilities haven't gained much experience. In addition, many tourism attraction lack further knowledge of the disabled tourism because they think constructing barrier-free facilities is unnecessary or serving disabled tourists will decrease their operating revenue and increase insurance cost. To solve those problems needs the cooperation and coordination of tourism enterprises and intensifying the propaganda for concept of the disabled tourism.

Analysis of the revolutionary game model between tourism enterprises and attraction.

Hypotheses of the model. Suppose the tourism enterprise are either engaged in or not the disabled tourism and the probability of encouragement is $\mathrm{x}$, then other relevant parameters of benefits are as follows.(1) The tourism enterprises which engaged in the business would gain direct economic benefit E1, direct cost $\mathrm{C}$ as well as government subsidies A1.When tourism attraction give them support (like ticket discount, etc. ), they can decrease cost and get benefit F, reputational benefits (T); if tourism attraction don' t do so, they have to pay extra cost D1.(2) The tourism enterprises which not engaged in the business would have potential lose $M$ of the business when getting the support from tourism attraction and is not affected when tourism attraction don't encourage the disabled tourism. Suppose the tourism attraction either encourage or not the disabled tourism and, then other relevant hypotheses are as follows.(1) When tourism attraction encourage the disabled tourism, if travel agencies aren't engaged in the business, then tourism attraction would enjoy government subsidies A2, extra construction loss B ; if travel agencies are engaged in the business, tourism attraction would enjoy reputational benefits $S$, construction cost B, government subsidies A2, direct economic benefit increase E2.(2)When tourism attraction don't encourage the disabled tourism, if travel agencies are engaged in the business, then tourism attraction would suffer indirect loss D2; if travel agencies don't engage in the business, tourism attraction wouldn't be affected.

Construction of the model. Through constructing revenue function of the tourism enterprises and attraction for the disabled in all possible situation based on parameters, the game matrix of tourism enterprises and attraction can be described as the table 1 .

Table 1 The evolutionary model of tourism enterprise and tourist attraction

\begin{tabular}{cccc}
\hline \multicolumn{2}{c}{ Game-agents and their strategies } & \multicolumn{2}{c}{ Tourism enterprise } \\
\cline { 3 - 4 } & & Engaged & Not engaged \\
\hline Tourist & Support & $E 2+A 2+S-B, E 1+F+T-C$ & $A 2+S-B,-M$ \\
attraction & Nonsupport & $-D 2, E 1-C-D 1$ & 0,0
\end{tabular}

Explain: due to the high construction cost of barrier-free facilities, only when receiving supportive policy (encouragement) from the government can those facilities be well equipped. Therefore, in the process of asymmetric game between tourism attraction and travel agencies, it can be directly assumed that government would give subsidies A2 to tourism attraction which support the disabled tourism.

The replicated dynamic equations and evolutionary stable strategy of the model.

For tourism enterprises, the replicated dynamic equations of engaging in the disabled accessible tourism is:

$$
F(x)=x(U x 1-\overline{U x})=x(1-x)[y(F+T+M+D 1)+E 1-C-D 1]
$$

Suppose $F(y)=d y / d t=0$, the results can be:

$$
x 1=0, x^{2}=1, y^{*}=\frac{C+D 1-E 1}{F+T+M+D 1}
$$


According to the stability theorem of evolutionary game theory, when $\mathrm{F}^{\prime}\left(\mathrm{x}^{*}\right)<0, \mathrm{x}^{*}$ is the ESS. When $y^{\prime} y^{*}, F(x)$ remains equal to 0 , that is to say, when the possibility of tourism attraction's support for the disabled to travel here is $\mathrm{y}^{*}$, any initial proportion of tourism enterprises engaged and not engaged in the tourism is stable. When $\mathrm{y}<\mathrm{y}^{*}$, on an interval of $(0,1)$ exists $\mathrm{F}^{\prime}(\mathrm{x})<0$ all the time, and simultaneously the replicated dynamic equation of tourism enterprises has two equilibrium points- $x 1^{*}=0, x 2^{*}=1$. And because $F^{\prime}(0)<0, F^{\prime}(1)>0$, thus when $y<y^{*}, x 1^{*}=0$ is the only ESS in the game between tourism enterprises and attraction. That proves when tourism attraction are reluctant to welcome disabled tourists' coming, it would cause tourism enterprises to gradually discard and finally deteriorate to an imperfect state (discourage, unengaged in). When $\mathrm{y}>\mathrm{y}^{*}$, on an interval of $(0,1)$ exists $\mathrm{F}^{\prime}(\mathrm{x})<0$ all the time, and simultaneously the replicated dynamic equation of tourism enterprises still has two equilibrium points- $x 1^{*}=0, x 2^{*}=1$. But because $F^{\prime}(0)>0, \quad F^{\prime}(1)<$ $0, \quad x 2^{*}=1$ is the only ESS in the whole game. That proves when tourism attraction support the disabled tourism, tourism enterprises would be willing to be engaged in this business and thus benign interaction can be made between the two stakeholders. Therefore the ideal state (support, engaged in) can be made.

For tourism attraction, the replicated dynamic equation is:

$$
F(y)=y(U y 1-\overline{U y})=y(1-y)[x(E 2+D 2)+A 2+S-B]
$$

Suppose $\mathrm{F}(\mathrm{y})=\mathrm{dy} / \mathrm{dt}=0$, the results can be:

$$
y 1=0, y 2=1, x^{*}=\frac{B-S-A 2}{E 2+D 2}
$$

Similarly, according to the stability theorem of evolutionary game theory, it can be known: When $\mathrm{x}=\mathrm{x}^{*}$, the possibility that tourism attraction welcome the disabled tourists' coming is stable in any possible situation. When $\mathrm{x}<\mathrm{x}^{*}, \mathrm{y} 1^{*}=0$ is the only ESS in the game between tourism enterprises and attraction. That proves when the possibility that tourism enterprises lead the disabled tourists to tourism attraction is not high, tourism attraction would think it is useless to spend manpower, material resources and funds in formulating regulation of ticket discount and installing barrier-free facilities. Tourism attraction would further gradually overlook the needs of the disabled, a special social group, and change their attitude to discouraging the disabled' coming. When $\mathrm{x}>\mathrm{x}^{*}, \mathrm{y} 2 *=1$ is the only ESS in the whole game. That proves when the possibility that tourism enterprises lead the disabled tourists to tourism attraction is relatively high, tourism attraction would have a new understanding of tourism market and pay attention to the needs of the new customers ( the disabled). Tourism attraction would further complete relevant barrier-free facilities and provide various preferential regulations to occupy the newly subdivided market.

Analysis of the revolutionary game result. In the coordinate plane which describes the trend of asymmetric game, the phase graph is shown in Figure 1.

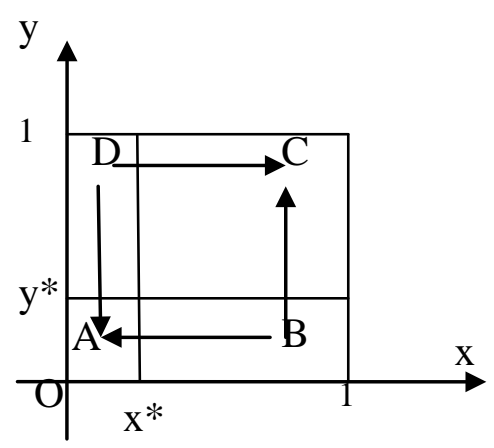

Figure 1

When the game between tourism enterprises and attraction develops forward the stable state (encouragement, engagement), region $\mathrm{C}$ should take up the major part of the area while the region $\mathrm{A}$ the minor one. Therefore the Nash Equilibrium should get minimum value, namely $\left(\mathrm{x}^{*}, \mathrm{y}^{*}\right)$ should be of small value. 
When C and D1 decreases and E1、F、T、M increases, $\mathrm{y} *$ would decrease. Tourism enterprise should strive to improve their service quality and utilization rate of their current property and staff to carry out the business with less cost C. For example, they can train their tour guide to learn sign language instated of hiring professional interpreter, or combine the disabled tourism business with other business. In addition, they should spend a little money on field survey of the equipment of barrier-free facilities in target tourism attraction in advance before organizing the disabled to travel there, and thus the extra cost D1 can be avoided. Tourism attraction should provide as much discount as possible for the tourism enterprises engaged in the business and strengthen the construction of soft infrastructure to brings tourism enterprises benefit $\mathrm{F}$ as decreased cost. Simultaneously, tourism attraction should intensify the propaganda of the disabled tourism to increase the pressure $\mathrm{M}$ on those not engaged. As an external promoter, government should enhance the propaganda of successful cases to enlarge the social influence and increase enterprises' reputational benefits $T$.

When B decreases and S, A2, E2, D2 increase, $x^{*}$ would decrease. Tourism attraction should import barrier-free facilities from foreign countries and government should decrease tax on those facilities or give more preferential policy after tax to them to decrease their construction cost B. On the one hand, Government, the dominant power of the disabled tourism, should give more support to the tourism attraction engaged in the disabled tourism to reduce the search cost of tourism enterprises for those tourism attraction and greatly increase the potential tourist flow volume of those tourism attraction with increased reputational benefits $\mathrm{S}$. On the other hand, government should provide more subsidies A2 to those tourism attraction engaged in the business to encourage and attract more tourism attraction to welcome the disabled tourists' coming. industry and social economy and bring much benefit ( $\mathrm{V}$ ) for the government in multiple aspects.

\section{Summary}

In the background that the tourism is enjoying sustainable development, this article discusses the dynamic asymmetric evolutionary game model between tourism enterprises and attraction and analyzes the stability of evolutionary strategy, at last, gets the following conclusions:(1)Tourism enterprises should enhance communication with tourism attraction. On the one hand, they should, based on their own ability of developing business, take the special needs of disabled people into consideration and improve their professional service quality for the disabled tourists to avoid causing mental stress on them and thus get negative influence. On the other hand, tourism enterprises should further merge the disabled tourism business with existing business to make full use of existing enterprise resources and by many ways reduce increased cost of the new business.(2)Tourism attraction should actively follow government's policy to complete the construction of barrier-free facilities as soon as possible and thus provide the special customer group of disabled people with a better barrier-free environment. Simultaneously, tourism attraction should enhance the train of staff with further professional knowledge of the disabled tourism, intensify the propaganda of the disabled travel business to attract potential customers and increase more pressure on those not engaged in the disabled tourism.

\section{References}

[1] Huang Xiaoxing, $\mathrm{Hu}$ Zhenpeng, $\mathrm{Fu}$ Chun et al. Evolutionary game analysis on the main stakeholders in ecotourism[J]. Ecological Economy, 2015, 31(1): 142-171.

[2] Zhao Liming, Chen Zhezhi, Liu Jiayue. Evolutionary game theory between local government and tourism enterprises in the context of a low-carbon economy[J]. Tourism Tribune, 2015, 30(1): 72-82.

[3] Aviad A. Israeli. A Preliminary Investigation of the Importance of Site Accessibility : Factors for Disabled Tourists [ J ]. Journal of Travel Research, 2002 , 41(1): 101- 104.

[4] Brian Goodall, Gaye Pottinger, Tim Dixon et al. Heritage Property, tourism and the UK Disability Discrimination Act [J]. Property Management.2004, 22(5) : 345-357. 
Supported by the Philosophy and Social Sciences Program of Sichuan Province(No. SC15B071), Supported by the Program of the Visual Computing and Virtual Reality Key Laboratory of Sichuan Province(No.KJ201420),Supported by the Program of the Department of Education of Sichuan Province(No.14SB0022), Supported by the Sichuan provincial innovation and entrepreneurship students Training Program(201410636045, 201510636087). 